\title{
Standing of nucleic acid testing strategies in veterinary diagnosis laboratories to uncover Mycobacterium tuberculosis complex members
}

\author{
Pedro Costa ${ }^{1,2}$, Ana Botelho ${ }^{1}$, Isabel Couto ${ }^{2,3}$, Miguel Viveiros $^{2,4}$ and João Inácio ${ }^{5 *}$ \\ Instituto Nacional de Investigação Agrária e Veterinária IP, Lisboa, Portugal \\ ${ }^{2}$ Grupo de Micobactérias, Unidade de Microbiologia Médica, Instituto de Higiene e Medicina Tropical da Universidade Nova de Lisboa, Lisboa, Portugal \\ ${ }^{3}$ Centro de Recursos Microbiológicos (CREM), Universidade Nova de Lisboa, Caparica, Portugal \\ ${ }^{4}$ Centro de Malária e Outras Doenças Tropicais, Instituto de Higiene e Medicina Tropical da Universidade Nova de Lisboa, Lisboa, Portugal \\ ${ }^{5}$ School of Pharmacy and Biomolecular Sciences, University of Brighton, Brighton, UK
}

\author{
Edited by: \\ Tarun Kumar Sharma, Translational \\ Health Science and Technology \\ Institute, India \\ Reviewed by: \\ Vinicius Maracaja-Coutinho, \\ Universidad Mayor, Chile \\ Sagarika Haldar, Translational Health \\ Science and Technology Institute, \\ India \\ *Correspondence: \\ João Inácio, School of Pharmacy and \\ Biomolecular Sciences, University of \\ Brighton, 802 Cockcroft Building, \\ Lewes Road, Brighton BN2 4GJ, UK \\ e-mail: j.inacio@brighton.ac.uk
}

Nucleic acid testing (NAT) designate any molecular approach used for the detection, identification, and characterization of pathogenic microorganisms, enabling the rapid, specific, and sensitive diagnostic of infectious diseases, such as tuberculosis. These assays have been widely used since the 90 s of the last century in human clinical laboratories and, subsequently, also in veterinary diagnostics. Most NAT strategies are based in the polymerase chain reaction (PCR) and its several enhancements and variations. From the conventional PCR, real-time PCR and its combinations, isothermal DNA amplification, to the nanotechnologies, here we review how the NAT assays have been applied to decipher if and which member of the Mycobacterium tuberculosis complex is present in a clinical sample. Recent advances in DNA sequencing also brought new challenges and have made possible to generate rapidly and at a low cost, large amounts of sequence data. This revolution with the high-throughput sequencing (HTS) technologies makes whole genome sequencing (WGS) and metagenomics the trendiest NAT strategies, today. The ranking of NAT techniques in the field of clinical diagnostics is rising, and we provide a SWOT (Strengths, Weaknesses, Opportunities, and Threats) analysis with our view of the use of molecular diagnostics for detecting tuberculosis in veterinary laboratories, notwithstanding the gold standard being still the classical culture of the agent. The complementary use of both classical and molecular diagnostics approaches is recommended to speed the diagnostic, enabling a fast decision by competent authorities and rapid tackling of the disease.

Keywords: nucleic acid testing, molecular diagnostics, Mycobacterium tuberculosis complex, Mycobacterium bovis, tuberculosis, bovine tuberculosis, SWOT analysis

\section{TUBERCULOSIS AND THE MYCOBACTERIUM TUBERCULOSIS COMPLEX}

Tuberculosis is an epidemic and serious infectious disease of global proportions, responsible for the death of one to two million people per year (WHO, 2011). The disease also affects wild and domestic animals, particularly livestock. Bovine tuberculosis is a zoonosis with high socio-economic impacts due to the low productivity of affected cattle, to the imposed restrictions on animal trade and products thereof, and due to the costs associated with the implementation of control and eradication programs (Schiller et al., 2011). This disease also raises important public health concerns, particularly in developing countries, where the main routes of transmission to humans are the contact with infected animals and ingestion of unpasteurized dairy products (Kubica et al., 2003; Etter et al., 2006; Rua-Domenech, 2006; Rodríguez et al., 2009; Michel et al., 2010; Pérez-Lago et al., 2013; Torres-Gonzalez et al., 2013). Nevertheless, there is some evidence of possible person-to-person transmission of the disease (Evans et al., 2007; Sunder et al., 2009). In most developed countries, bovine tuberculosis has been tackled during the last decades by costly eradication programs. However, the eradication of the disease has been hampered in many countries by the presence of wild animals which act as reservoirs of disease, among which are the European badger (Meles meles), the possum (Trichosurus vulpecula), the bison (Bison bison), the African buffalo (Syncerus caffer), the white-tailed deer (Odocoileus virginianus) and the wild boar (Sus scrofa) (Santos et al., 2010; Maas et al., 2013; Hardstaff et al., 2014).

Tuberculosis is caused by members of the Mycobacterium tuberculosis complex (MTC), a group of closely-related species including: M. tuberculosis (the predominant cause of human tuberculosis); " $M$. canettii" (a very rare MTC biotype); M. africanum (mainly associated to human tuberculosis in Africa); M. pinnipedii (the cause of endemic tuberculosis in 
several seal species); M. microti (with bank voles and other small rodents as natural hosts, rarely identified from other mammals); M. mungi (associated to tuberculosis in banded mongooses in Botswana); M. orygis (a recently described and less known rare species, with oryxes, waterbucks, and gazelles as potential hosts in Africa, and bovines and rhesus monkeys in South Asia); and $M$. bovis and M. caprae (the worldwide predominant cause of bovine and goat tuberculosis, respectively, but also causing disease in a wide range of domestic and wild animals, including humans) (Huard et al., 2006; Smith et al., 2009; Alexander et al., 2010; van Ingen et al., 2012; Broughan et al., 2013; RodriguezCampos et al., 2014). Although a rare event, infection with M. tuberculosis may occur in animals living in close contact with humans, such as pets, pigs, cattle and captive animals (Erwin et al., 2004; Amado et al., 2006; Schmidt et al., 2008; Mohamed et al., 2009; Botelho et al., 2014; Rodriguez-Campos et al., 2014). Although the differences in their epidemiology, namely geographic distribution and host preferences, virulence traits and antimicrobial susceptibility patterns (Brosch et al., 2000), MTC species share more than $99.9 \%$ genomic sequence homology, with very low levels of genetic diversity at the nucleotide level, and present identical 16S ribosomal gene sequences (Sreevatsan et al., 1997; Mostowy et al., 2005). The genome of these species has a size of approximately 4.4 million base pairs, which reflects the complexity of their life cycles as facultative intracellular parasites, and contains a higher GC content of about $65 \%$. The exchange of genetic material by horizontal gene transfer (HGT) events is apparently very rare among these species, which results in their mainly clonal evolution (Coros et al., 2008). However, recent whole-genome based studies have suggested that HGT may not be as rare as previously thought in MTC (Veyrier et al., 2009; Supply et al., 2013; Wang and Behr, 2014). The ancestor of all tubercle bacilli probably underwent major events of genetic exchange with unrelated environmental bacteria, which might have contributed to the evolution of those species (Gutierrez et al., 2005; Becq et al., 2007; Jang et al., 2008; Veyrier et al., 2011; Namouchi et al., 2012). Remarkable, some genomic islands were found to contain genes with putative or documented virulence functions, notably the Rv0986-8 operon, probably acquired from a gammaproteobacterial species and involved in the host cell parasitism (Rosas-Magallanes et al., 2006; Becq et al., 2007; Jang et al., 2008). The lack of more abundant HGT events among the MTC members may be a consequence of the organisms' solitary lifestyles within their hosts, preventing their contact with other bacterial species (Gutierrez et al., 2005; Smith et al., 2006; Jang et al., 2008).

The designation of the different members of the MTC as distinct formal species is somewhat controversial and challenges the usual concept of bacterial species, given the very reduced genome sequence diversity and the absence of major phenotypic differences within the complex. Indeed, these mycobacteria may be differentiated in species, subspecies or even host-adapted ecotypes depending on the strict taxonomical criteria used for interpretation (Rodriguez-Campos et al., 2014). Nevertheless, although genetically very similar, MTC members can be distinguished by stable molecular differences, such as single nucleotide (SNPs) and large sequence (LSPs) polymorphisms, whose analysis have been the basis of several evolutionary studies about these mycobacteria (Brosch et al., 2002; Mostowy et al., 2002, 2005). Comparative genomic analysis evidenced that modern MTC species probably evolved from a common ancestor through the accumulation of sequential and irreversible genomic deletions, named Regions of Difference (RDs), which has been important in generating genetic diversity within these closely related mycobacteria (Mahairas et al., 1996; Brosch et al., 1998, 2002; Behr et al., 1999; Gordon et al., 1999; Mostowy et al., 2002). The pattern of the presence or absence of these RDs in the genome of MTC members provides a molecular signature that can discriminate among these mycobacteria (Brosch et al., 2002; Mostowy et al., 2002; Huard et al., 2006; van Ingen et al., 2012). Other molecular markers, such as deletions of spacer sequences of the Direct Repeat (DR) locus and specific SNPs corroborate this discrimination among MTC members (Gutacker et al., 2002; Baker et al., 2004; Gutierrez et al., 2005; Huard et al., 2006; Smith et al., 2006; Alland et al., 2007). MTC members harboring animals as their main hosts share the absence of RD9 (present in M. tuberculosis) and other common features such as the deletion of specific DR spacers and common SNPs (Smith et al., 2006, 2009).

\section{CONVENTIONAL APPROACHES FOR THE CONFIRMATION OF TUBERCULOSIS IN ANIMALS}

In cattle, symptoms of tuberculosis often manifest later, so the clinical diagnosis is rare, especially in the course of control and eradication plans. In most developed countries, eradication plans of bovine tuberculosis mostly involve the culling of reactor animals and the laboratory testing of suspect tissue samples for the definitive confirmation of the presence of MTC, particularly of M. bovis. The screening of tuberculosis in live animals depends on immunological assays such as the single intradermal comparative cervical tuberculin (SICCT) and the interferon-gamma $(\mathrm{IFN}-\gamma)$ tests, which are based on the detection of cell-mediated immune responses. SICCT test is based in an observed delayed hypersensitivity reaction after an intradermal injection of bovine and avian tuberculin in animals. When tuberculin is injected into an animal whose immune system has been sensitized by infection with M. bovis, or by exposure to cross-reacting antigens, it triggers an inflammatory response and swelling at the injection site (Rua-Domenech et al., 2006). However, the sensitivity of this test is moderate with estimates typically in the range 50-60\%. The IFN- $\gamma$ test is an enzyme immunoassay based on the evaluation of cytokine released by lymphocytes previously sensitized with tuberculin and is generally used as a complement of the SICCT test (Gormley et al., 2006). The IFN- $\gamma$ test is generally accepted to have a higher sensitivity than the SICCT test but does not have a sufficiently high specificity to allow its use as a general screening tool. Antibodies in measurable quantities are only produced in later stages of the disease (Neill et al., 2001; Pollock and Neill, 2002) and, consequently, diagnostic methods based on the humoral response usually yield low sensitivities (Pollock et al., 2005). Nevertheless, these tests may be of value in identifying animals with more advanced disease and therefore more likely to be infectious.

The detection of MTC bacteria in animal tissues is mainly based in lengthy and cumbersome conventional methods, 
involving the examination of Ziehl-Neelsen stained smears, histopathology, and culture in selective media, followed by biochemical or molecular identification of typical mycobacteria colonies. The microscopic observation of acid-fast mycobacteria is non-specific and highly insensitive, particularly in the case of paucibacillary forms of tuberculosis. Culture remains the goldstandard method to confirm tuberculosis infection but requires several weeks to obtain positive results due to the extremely fastidious growth of tuberculous mycobacteria. A variety of different media has been developed for the cultivation of mycobacteria including egg-based media (e.g., Stonebrink's medium and Löwenstein-Jensen with added pyruvate), agar-based media eventually enriched with serum or blood (e.g., Middlebrook 7H10 and 7H11), and liquid media (e.g., Middlebrook 7H9) (Gormley et al., 2014). The introduction of automatic radiometric (e.g., BACTEC 460) and fluorometric (e.g., BACTEC 9000MB or MGIT 960) equipments contributed to shorten the culture time (Drobniewski et al., 2003; Hines et al., 2006). Culture has a high specificity but is not particularly sensitive, especially when using lymph node samples without observable lesions, even when animals are positive for SICCT or IFN- $\gamma$ tests (Pollock and Neill, 2002; Rua-Domenech et al., 2006). The results of culture assays may be also affected by several factors, such as the decontamination procedures of samples, which can also have a harmful effect on mycobacteria, as well as the growth media and incubation conditions used and the constrained distribution of mycobacteria in tissues (Corner, 1994; Corner et al., 2012; Gormley et al., 2014). Moreover, conventional laboratory diagnosis does not routinely discriminate between the species of the MTC. In most circumstances, phenotypic and biochemical assays able to discriminate MTC members, such as the assessment of oxygen requirements, niacin accumulation, nitrate reductase activity, resistance to pyrazinamide or use of glycerol and pyruvate by the MTC strains (Wayne and Kubica, 1986; Grange et al., 1996) are slow, may yield ambiguous results and may be limited by a degree of technical complexity that rule out its implementation in routine diagnostics (Niemann et al., 2000).

\section{NUCLEIC ACID TESTING OF VETERINARY-RELEVANT MTC BACTERIA}

The field of molecular diagnostics met tremendous technological developments in the last two decades, and several strategies and applications have been described to identify and characterize MTC mycobacteria cultures and to directly detect these organisms from a wide variety of matrices, including animal tissues. The first molecular diagnostic methods have emerged in the 70s of the last century, when DNA probes labeled with radioactive isotopes were used to detect complementary DNA. These methods have evolved after the introduction of restriction enzymes, used to cleave the microbial genomes. The resulting fragments were then separated by gel electrophoresis, transferred to a membrane and subjected to hybridization with labeled DNA probes in a procedure known as Southern blotting in tribute to the original inventor of the technique (Southern, 1975). Over time, the hybridization procedures were improved, including the labeling of DNA probes with reporter molecules safer and easier to use, such as biotin or digoxigenin (Langer et al., 1981), allowing a colorimetric detection of hybridization results, or with fluorescein and other luminescent molecules (chemiluminescent reaction). Several applications are described in the literature where the direct hybridization with DNA probes allowed the identification of cultured M. bovis and other MTC members (Picken et al., 1988; Thierry et al., 1992; Cousins et al., 1993; Fisanotti et al., 1997). However, despite the high specificity, the applications based on direct hybridization were never really adopted in the routine clinical diagnosis of animal tuberculosis, since they are very labor intensive, costly, slow and insensitive.

The introduction of in vitro nucleic acids amplification technologies enabled the development of new tools for the rapid, sensitive, and specific detection and identification of pathogenic microorganisms, including tuberculous mycobacteria. The most commonly used technology is based on the polymerase chain reaction (PCR), introduced in the mid-80s of last century (Saiki et al., 1985, 1988). The first applications of PCR for the detection and identification of veterinary-relevant MTC members were published soon after (Cousins et al., 1991; Plikaytis et al., 1991; Wards et al., 1995). The real-time PCR was introduced in the mid-90s of last century (Heid et al., 1996; Williams, 2009) and was a very significant advancement in PCR technology that greatly contributed to a wider use of molecular diagnostics technologies. Real-time PCR also allows quantifying the numbers of copies of the template DNA initially present in a sample. Although the significant advances in the development of novel molecular diagnostic assays toward a faster and accurate detection of MTC in human samples, only a few assays have been described for detecting these agents directly in animal tissues, particularly in fresh tissues from livestock (Coetsier et al., 2000; Roring et al., 2000; Taylor et al., 2001, 2007; Parra et al., 2008; Costa et al., 2013a; Araújo et al., 2014). Most of these molecular approaches are PCRbased and target specific polymorphisms, insertion sequences, particularly the IS6110, and RDs in the genome of MTC members (Liébana et al., 1995; Wards et al., 1995; Miller et al., 1997; Niemann et al., 2000; Taylor et al., 2001, 2007; Pounder et al., 2010; Thacker et al., 2011; Reddington et al., 2012). A higher number of PCR-based applications were described for the identification of MTC members using DNA extracted from cultures as template. Approaches such as the analysis of SNPs of the gyrB gene, and of other genes, or the assessment of the structure of variable DRs or of LSPs in the genome of MTC members have been described that effectively discriminate between these species (Niemann et al., 2000; Parsons et al., 2002; Huard et al., 2003; Djelouadji et al., 2008; Pinsky and Banaei, 2008; Halse et al., 2011). Several RDs-targeted assays have been proposed for MTC species discrimination, usually involving standard PCR reactions and analysis of products by gel electrophoresis (Warren et al., 2006; Chen et al., 2007; Allix-Béguec et al., 2010), real-time PCR using intercalating fluorescent dyes and melting curve analysis (Pinsky and Banaei, 2008; Pounder et al., 2010) and, to a lesser extent, dual labeled hydrolysis probes (Halse et al., 2011; Reddington et al., 2011, 2012; Costa et al., 2014a,b).

In the context of molecular microbiological diagnostics, the DNA fragments amplified by PCR, or by any other nucleic acid amplification technology, can also be analyzed by hybridization with DNA probes immobilized on solid supports (reverse 
hybridization) such as nylon or nitrocellulose membranes. The reverse hybridization technology enables the detection of multiple genomic targets in a single test, a format commonly referred to as macroarray in which different probes are immobilized in specific positions of membranes as dots (dot blots) or lines (line blots). The target DNAs are labeled during its amplification, for example using biotinylated primers, and the occurrence of hybridization with their complementary probes is signalized by an enzymatic step yielding a colorimetric or chemiluminescent signal. Several systems based on this format have been described for the detection, identification and even typing (e.g., spoligotyping) of veterinary-relevant MTC members and commercial diagnostic systems are also available (Padilla et al., 2003, 2004; Duarte et al., 2008).

\section{MAJOR CHALLENGES OF TUBERCULOSIS NUCLEIC ACID TESTING}

It is widely recognized that the analytical sensitivity of amplification-based nucleic acid testing is extremely high, often allowing the detection of single copies of the target nucleic acids in the reaction mixture. However, the performance of these methods is many times unsatisfactory when used for the direct detection of pathogen's nucleic acids directly in samples, yielding false negative results. A problem still largely unsolved concerns the processes of extraction and purification of nucleic acids from biological samples, particularly from tissues. Indeed, most of the amplification-based assays described for detecting MTC nucleic acids directly in fresh or formalin-fixed paraffin-embedded animal tissues only yield a moderate sensitivity, usually up to $75 \%$ when compared to the reference bacteriological culture, particularly when testing tissues without the characteristic lesions (Liébana et al., 1995; Coetsier et al., 2000; Roring et al., 2000; Taylor et al., 2001, 2007; Parra et al., 2008; Thacker et al., 2011). This limitation is mostly related to the increased complexity for disrupting and recovering genomic DNA from the tough mycobacterial cells, which harbor complex walls, and to the inefficiency of the extraction procedures from affected animal tissues, especially those exhibiting strong fibrosis, calcification, and with no histological evidence of acid-fast bacteria (Liébana et al., 1995; Taylor et al., 2007; Amaro et al., 2008; Parra et al., 2008; Costa et al., 2013a; Radomski et al., 2013). The presence of amplification inhibitors in crude tissue extracts, and of large amounts of co-extracted host eukaryotic DNA, often represent an additional problem. Target mycobacteria are located within phagosomes, within a host cell and within a granuloma, making DNA extraction from these organisms more challenging (Radomski et al., 2013). The availability of efficient, simple to use and affordable mycobacterial nucleic acids extraction processes adapted to difficult biological matrices, such as animal tissues, is still an unmet need that has hindered a more widespread routine use of molecular methods for the detection of MTC members in the veterinary microbiology laboratory (Cunha and Inácio, 2014).

Important in the context of developing nucleic acid testing assays for tuberculosis is also the availability of adequate gold standard diagnostics methods to validate and assess the performance of those assays (Cunha and Inácio, 2014). The culture of tissue samples for the isolation of MTC members, followed by molecular or biochemical identification procedures, is usually the gold-standard method to validate alternative diagnostic assays. However, it is widely known that bacteriological culture is slow and laborious and can yield ambiguous or false-negative results, e.g., due to the presence of non-viable mycobacteria, raising concerns about its effectiveness as comparison reference method (Liébana et al., 1995; Santos et al., 2010; Costa et al., 2013a). As mentioned above, the results of culture assays may be affected by several factors, including the constrained distribution of mycobacteria in affected tissues (Corner et al., 2012; Gormley et al., 2014).

\section{RE-EMERGING STRATEGIES TO UNCOVER ANIMAL-RELEVANT MTC MEMBERS}

An option that has been explored to enhance the sensitivity of PCR techniques for detecting MTC bacteria directly from biological samples involves the implementation of more effective mycobacterial DNA extraction and purification methods. For example, Taylor and colleagues were able to increase the M. bovis detection sensitivity by PCR in bovine tissues, with visible lesions, from 70 to $91 \%$, after the inclusion of an additional cell disruptive step of freeze-thaw cycles with liquid nitrogen in the DNA extraction process (Taylor et al., 2007). Mechanical disruption using bead-beating approaches was also shown to be more effective for the recovery of mycobacterial DNA from tissues (Amaro et al., 2008; Radomski et al., 2013). The use of sequence capture or immunomagnetic separation (IMS) approaches was also previously proposed for recovering higher yields of mycobacterial DNA, particularly of $M$. bovis, from samples such as tissues, soil and feces (Roring et al., 2000; Taylor et al., 2001; Sweeney et al., 2006, 2007; Parra et al., 2008; Garbaccio and Cataldi, 2010), with different degrees of success. Noteworthy, IMS strategies specifically targeting $M$. bovis were very recently described by Stewart et al. (2013), allowing great sensitivity improvements for the culture and molecular detection of this mycobacterium from tissue specimens. IMS is a physical cell separation technique able to selectively capture and concentrate MTC bacteria from complex matrices using magnetic beads coated with specific polyclonal or monoclonal antibodies or other binders (Stewart et al., 2013; Grant and Stewart, 2014). After the nucleic acid extraction from the concentrated whole cells, captured on the magnetic beads, genomic targets such as the MTC-specific IS6110 can be analyzed by PCR or other molecular techniques (Stewart et al., 2013; Grant and Stewart, 2014). Nevertheless, albeit promising, these DNA extraction approaches involve additional experimental steps and complexity, and usually require more expensive equipments and consumables, which currently limit their wider use for the routine laboratorial diagnosis of animal tuberculosis.

An established PCR-based strategy to increase the detection sensitivity thresholds of low-copy number DNA targets is the nested PCR, although this higher sensitivity needs to be balanced against the associated increased risk of cross contamination of samples. Thus, the use of nested PCR approaches, as for any diagnostics techniques, requires very strict good practice standard conditions for molecular analysis and an effective quality assurance and control (Costa et al., 2013a, 2014b; Kozlovac and Schmitt, 2014; Saunders and Sharp, 2014). Previous studies found 
no significant improvements in the detection of MTC members in animal tissue samples when using nested PCR assays, including with real-time PCR formats (Wards et al., 1995; Taylor et al., 2007; Thacker et al., 2011). However, it is widely know that the performance of PCR detection systems is highly dependent on the efficiency of the primers and probes, even when using the same genomic targets such as the MTC-specific IS6110 element (Savelkoul et al., 2006). Recently published studies, including from our group, highlighted the usefulness of re-emerging nested PCR strategies, including a real time PCR format, for a more sensitive detection of MTC genomic targets directly in animal tissue extracts (Costa et al., 2013a, 2014b; Araújo et al., 2014). Costa and colleagues optimized an IS6110-targeted nested real time PCR approach allowing the direct detection of MTC members in animal tissue specimens, particularly from bovine, with very high sensitivity, specificity and positive and negative predictive values (Costa et al., 2013a). The inclusion of a first step of conventional IS6110-targeted PCR amplification, whose product is then used as template for a second Taqman ${ }^{\circledR}$-based real time PCR, allowed to increase the sensitivity of the detection assay to near $100 \%$ (using culture as gold-standard). The duplex use of a $\beta$-actin gene targeted probe, with complementary targets in most mammals, allowed the assessment of amplification inhibitors in the tissue samples. Other recently published study by Araújo and colleagues described a similar nested real time PCR approach targeting the $T b D 1$ region of $M$. bovis in bovine and bubaline tissue homogenates (Araújo et al., 2014). The $T b D 1$ region appears to be present exclusively in the genomes of $M$. bovis, M. africanum, "M. canettii" and in ancestral strains of M. tuberculosis (Brosch et al., 2002), the last three taxa being very infrequently or not associated at all with infection in animals.

The discrimination between MTC members is important for an accurate diagnosis and epidemiological assessment of mycobacterial disease. In the last two decades, the accumulating knowledge of the nucleotide sequences of several genes, and of the whole genomes, of these species has allowed the development of novel molecular assays for their identification. As mentioned earlier in this review, the pattern of the presence or absence of specific RDs in the genome of MTC members provides a highly specific molecular signature that can accurately discriminate among these species. Furthermore, targeting LSPs instead of SNPs (e.g., in gyrB and other genes) to discriminate between MTC members may allow the development of more robust PCR-based assays for use in the routine diagnostics framework of veterinary laboratories. PCR-based detection assays targeting SNPs are more difficult to optimize and may be less robust, requiring a much more strict control of the experimental conditions to maintain the specificity. Several strategies targeting specific RDs were recently described for the identification of MTC members, also by our group, that focused mainly in the species of the complex most commonly associated with tuberculosis in livestock and other animals (Costa et al., 2014a,b). A two-step identification strategy was thus developed, comprising two sequential TaqManbased multiplex real-time PCR reactions. The first step allows the identification as MTC, by targeting the IS6110 element, or as a mycobacterial species, if only a $16 \mathrm{~S}$ rDNA product is detected in the duplex amplification reaction. If a MTC member is identified, the subsequent RDs-targeted triplex real time PCR allow the identification to the species level as $M$. bovis, $M$. bovis BCG, $M$. caprae or M. tuberculosis, according to their distinct patterns of presence or absence of RD1, RD4 and RD9 loci. This assay is faster and simpler than other SNPs-targeted restriction analysis or reverse line probe hybridization-based molecular assays, since it bypasses any post-amplification experimental steps.

\section{FUTURE PROSPECTS FOR THE MTC NUCLEIC ACID TESTING}

Nucleic acid testing assays for pathogens detection and identification are still mostly "in house" optimized in veterinary diagnosis laboratories, usually demanding highly qualified personnel and sophisticated and expensive facilities, equipment and consumables (Cunha and Inácio, 2014). Therefore, it is necessary that these technologies become simpler, standardized, and affordable to make them effectively and widely used in routine clinical laboratories, including in low-resource laboratories and in the developing world where animal and human tuberculosis is still a huge scourge. Isothermal nucleic acids amplification processes, such as Loop-Mediated Isothermal Amplification (LAMP) (Notomi et al., 2000), could facilitate the integration of nucleic acid testing strategies into bench molecular diagnostics kits independent of the utilization of sophisticated equipments (Niemz et al., 2011). The high potential of LAMP for the development of improved nucleic acid detection strategies fully justifies the increasing number of reports on its utilization, including for the detection of M. tuberculosis in sputum (Iwamoto et al., 2003; Boehme et al., 2007; Pandey et al., 2008; Aryan et al., 2010, 2013; Geojith et al., 2011; Zhang et al., 2011; Yuan et al., 2014). LAMP relies upon an auto-cycling strand displacement DNA synthesis and is more tolerant to the presence of inhibitory substances such as blood, serum, plasma or heparin (Notomi et al., 2000). The reaction runs very rapidly in the presence of template nucleic acids and deoxynucleoside triphosphates, at a constant temperature (usually between 60 and $65^{\circ} \mathrm{C}$ ), and provides high amplification efficiency with a detection limit and specificity comparable to those of standard PCR. The detection of amplified products by electrophoresis is not practical outside the laboratory but disposable generic strips for the lateral flow detection of nucleic acids, although still very expensive, are already commercially available (Chowdry et al., 2014). These chromatographic strips can detect biotin-labeled DNA fragments hybridized with complementary FITC-labeled probes. FITC is detected in the strips by the formation of complexes with gold-conjugated anti-FITC antibodies. Our group is exploring the integration of LAMP with these chromatographic strips for detecting veterinary-relevant MTC members, particularly M. bovis, by targeting specific RD elements, aiming the development of novel equipment-free molecular diagnostic kits for bovine tuberculosis (Costa et al., unpublished).

Other technological fields experiencing great developments are microfluidics and nanotechnology (Granberg et al., 2014; Teles and Fonseca, 2014). The procedures required for the molecular detection of pathogens in biological samples, including nucleic acids extraction and detection of specific genomic targets can all be conceptually integrated into miniaturized microfluidic systems, enabling the development of promising molecular diagnostics devices commonly referred to as Lab-on-a-Chip (Granberg 
et al., 2014; Teles and Fonseca, 2014). Particularly interesting have been the internationally significant research efforts invested in the development of a next generation of low-cost microfluidic paper-based analytical devices (Martinez et al., 2007, 2010; Vella et al., 2012; Rozand, 2014), also known as paperfluidics or Labon-Paper (Costa et al., 2013b). These devices are based on the definition of microchannels and test zones on hydrophilic paper via the patterning of walls of hydrophobic polymers, photoresist, or wax. Movement of fluids within channels is by capillarity and thus independent multi-analyte assays can be conducted that do not require use of pipettes, pumps, or electric energy. Multiple detection zones for different target compounds are created by deposition of reagents such as enzymes and antibodies on the paper surface (Martinez et al., 2010). When the sample reaches the detection zone, a reaction occurs and a color is developed. Assays for detecting total proteins, cholesterol, and glucose in fluids have been demonstrated and more specific biorecognition assays usually involve antibody-antigen interactions (Martinez et al., 2010; Vella et al., 2012; Costa et al., 2013b). We and other groups are trying to adapt paperfluidics platforms for the development of nucleic acid testing assays (Araújo et al., 2012; Veigas et al., 2012; Costa et al., 2013b), a major largely unsolved problem being the efficiency of immobilization processes of nucleic acid probes on the cellulosic paper matrices. In this context, very recently, Rosa and colleagues described a novel methodology to capture labeled-DNA strands and hybrids on paper, using MTC nucleic acid templates as model, via the anchoring of antibodies with a fusion protein that combines a carbohydrate binding module (CBM), with high affinity to cellulose, and the ZZ fragment of the staphyloccocal protein A, which recognizes IgG antibodies via their Fc portion (Rosa et al., 2014). Antibodies immobilized on paper matrices via CBM-ZZ were able to capture appropriately labeled (biotin, fluorescein) DNA strands and DNA hybrids. The efficiency of the capture of labeled-DNA by this strategy was significantly higher when compared with a physical adsorption method, which constitutes an important step toward the development of affordable paperfluidics-based molecular diagnostic tests.

Nanotechnologies have also sparked interest in the development of new diagnostic tests and biosensors, including nucleic acid testing strategies, taking advantage of the unique properties that many materials exhibit at the nanoscale (Teles and Fonseca, 2014). Gold-nanoparticles, in particular, are already used frequently in research for the molecular diagnostics of MTC bacteria (Liandris et al., 2009; Costa et al., 2010, 2013b; Veigas et al., 2012). In an example, gold nanoparticles conjugated with oligonucleotide probes (gold-nanoprobes) allow the colorimetric detection of complementary DNA targets (Baptista et al., 2008). In solution, monodisperse gold-nanoprobes appear red and exhibit a Surface Plasmon Resonance (SPR) band around $520 \mathrm{~nm}$. In contrast, a solution containing aggregated gold-nanoprobes appears blue, corresponding to a characteristic shift in the SPR band to higher wavelengths. The presence of complementary DNA targets prevents aggregation of the gold-nanoprobes and the solution remains red; non-complementary targets do not prevent goldnanoprobe aggregation resulting in a visible color change to blue. This gold-nanoprobe non-cross-linking method has been applied for the colorimetric identification of $M$. bovis and other MTC mycobacteria, for example based in the detection of their PCR-amplified gyrB genes (Costa et al., 2010).

Finally, over the last years, advanced high-throughput sequencing technologies, and associated bioinformatics, have generated massive amounts of sequence information, also for relevant viral, parasitic and bacterial animal pathogens (Cantacessi et al., 2014; Van Borm et al., 2014), with the possibility to generate highly redundant genome or metagenomic sequences for just a few tens or hundreds of dollars (Joseph and Read, 2010; Köser et al., 2012). In this context, there are tens or even hundreds of genome sequences currently available for an increasing number of individual microbial pathogenic species, with a particular focus for MTC members such as M. tuberculosis and M. bovis (Roetzer et al., 2013; Coll et al., 2014). The analysis of SNPs and other genetic polymorphisms information derived from Whole Genome Sequencing (WGS) studies is allowing to uncover the natural variation of MTC populations and the relation of these pathogens with their hosts, including virulence, drug susceptibility and immune modulator determinants relevant to the clinical manifestations of disease (Ford et al., 2012; Coll et al., 2014). With the rapid decrease in DNA sequencing costs, it is foreseen that WGS and metagenomics technologies will play an increasing role in clinical microbiology laboratories, particularly for molecular epidemiology studies (for surveillance and outbreak investigation) and genotypic antimicrobial susceptibility testing, with a focus for fastidious microorganisms such as MTC species (Biek et al., 2012; Köser et al., 2012; Roetzer et al., 2013). High throughput sequencing technologies and metagenomics may be also useful for detecting novel pathogens, or variants of known pathogens, that leads to false negative results using the standard diagnostic tests (Köser et al., 2012). In the coming years we will continue to experience tremendous developments in highthroughput sequencing technologies that will shape the design of novel diagnostics and disease intervention strategies, including in the veterinary field (Cantacessi et al., 2014; Van Borm et al., 2014).

\section{SWOT ANALYSIS FOR MTC NUCLEIC ACID TESTING IN VETERINARY LABORATORIES}

Despite the great advantages normally associated with nucleic acid testing technologies, for example in terms of specificity, sensitivity and speed of response, veterinary laboratories face several challenges in the implementation and use of these methods (Cunha and Inácio, 2014). In Table 1 we disclose a selfexplanatory SWOT analysis summarizing our view on the current most relevant Strengths, Weaknesses, Opportunities, and Threats associated to the use of nucleic acid testing strategies to uncover MTC members in veterinary diagnosis laboratories.

\section{CONCLUSIONS}

Nucleic acid testing will be increasingly used in the veterinary context. Identification of MTC cultures is relatively straightforward when using nucleic acid testing approaches but the molecular detection of these organisms directly in tissue specimens remains extremely challenging. A problem still largely unsolved concerns the processes of extraction and purification of mycobacterial nucleic acids from biological 
Table 1 | SWOT analysis for MTC nucleic acid testing in veterinary laboratories.

Strengths
- Overall higher diagnostic specificities and sensitivities
- High discriminatory power
- Short time-to-result
- High sample throughput
- Multiplexing capability
- Possibility to target antimicrobial resistance and virulence associated
genes or polymorphisms
- Possibility to quantify target nucleic acids in samples
- Wide range of public databases and bioinformatics tools available for
analysis of molecular data

\section{Weaknesses}

- Requirement for more expensive facilities, reagents and consumables

- Requirement for more technically complex procedures

- Potential for the occurrence of false positives due to contamination by target nucleic acids

- Potential for the occurrence of false negatives due to difficulties in extracting and purifying MTC nucleic acids from tissues

- Nucleic acid testing does not usually differentiate between viable and nonviable mycobacteria

\section{Opportunities}

\section{Threats}

- Growing demand for diagnostic tests for food-producing animals

- Demand for "point-of-care" diagnostic tests

- Educational efforts to disseminate nucleic acid testing

- Automation of nucleic acid tests

- Demand for more efficient DNA extraction and purification assays

- Microfluidics and nanotechnologies are becoming more mature for developing alternative nucleic acid tests

- Next generation sequencing and the "population genomics era"

- Increasing amounts of genetic information available from public databases

- Less strict regulations in the veterinary sector can facilitate a more rapid adoption of new diagnostic technologies matrices. Noteworthy, the use of re-emerging nested PCR strategies may prove useful for detecting M. bovis and other MTC members in animal tissue specimens. Isothermal DNA amplification technologies, microfluidics and nanotechnology may also soon provide the basis for more efficient and widespread lowcost diagnostic devices targeting MTC organisms. Next generation sequencing and high-throughput metagenomics are forecasted to greatly shape our future understanding about microbial pathogens and will contribute for designing enhanced diagnostics and intervention strategies. Yet, we do not anticipate the complete replacement of culture-based diagnostics, which is also subject to improvements, by nucleic acid testing technologies. On the contrary, the real added value of molecular diagnostics will be in their complementarily use with conventional microbiological tests, allowing the collection and analysis of multivariate phenotypic and genotypic characteristics of pathogenic microorganisms.

\section{AUTHOR CONTRIBUTIONS}

All authors contributed substantially to the conception and preparation of this review, revised it critically, approved the final version to be published, and agreed to be accountable for all aspects of the work.

\section{ACKNOWLEDGMENTS}

João Inácio acknowledges funding from the Portuguese Science Foundation (FCT), Portugal (PTDC/CVT/111634/2009 research project); Pedro Costa was a recipient of a $\mathrm{PhD}$ grant from FCT (SFRH/BD/64136/2009).

\section{REFERENCES}

Alexander, K. A., Laver, P. N., Michel, A. L., Williams, M., van Helden, P. D., Warren, R. M., et al. (2010). Novel Mycobacterium tuberculosis complex
- Pressure to keep a low price per analysis in the veterinary sector

- Lack of harmonization of nucleic acid testing between different laboratories

- Conservatism of medical personnel and technicians in the adoption and use of new diagnostics technologies

- Difficulty in finding good gold standard diagnostic methods to validate novel nucleic acid tests

pathogen, M. mungi. Emerg. Infect. Dis. 16, 1296-1299. doi: 10.3201/eid1608. 100314

Alland, D., Lacher, D. W., Hazbon, M. H., Motiwala, A. S., Qi, W., Fleischmann, R. D., et al. (2007). The role of large sequence polymorphisms in generating genomic diversity in clinical isolates of Mycobacterium tuberculosis and their utility in phylogenetic analysis. J. Clin. Microbiol. 46, 39-46. doi: 10.1128/JCM.02483-05

Allix-Béguec, C., Fauville-Dufaux, M., Stoffels, K., Ommeslag, D., Walravens, K., Saegerman, C., et al. (2010). Importance of identifying Mycobacterium bovis as a causative agent of human tuberculosis. Eur. Respir. J. 35, 692-694. doi: $10.1183 / 09031936.00137309$

Amado, A., Albuquerque, T., Gonçalves, A., Duarte, E., Botelho, A., Fernandes, T., et al. (2006). Tuberculosis in mandrills at the Lisbon zoo. Vet. Rec. 159:643. doi: 10.1136/vr.159.19.643

Amaro, A., Duarte, E., Amado, A., Ferronha, H., and Botelho, A. (2008). Comparison of three DNA extraction methods for Mycobacterium bovis, Mycobacterium tuberculosis and Mycobacterium avium subsp. avium. Lett. Appl. Microbiol. 47, 8-11. doi: 10.1111/j.1472-765X.2008.02372.x

Araújo, A. C., Song, Y., Lundeberg, J., Stahl, P. L., and Brumer, H. 3rd. (2012). Activated paper surfaces for the rapid hybridization of DNA through capillary transport. Anal. Chem. 84, 3311-3317. doi: 10.1021/ac300025v

Araújo, C. P., Osório, A. L., Jorge, K. S., Ramos, C. A., Filho, A. F., Vidal, C. E., et al. (2014). Detection of Mycobacterium bovis in bovine and bubaline tissues using nested-PCR for TbD1. PLoS ONE 9:e91023. doi: 10.1371/journal.pone.0091023

Aryan, E., Makvandi, M., Farajzadeh, A., Huygen, K., Alvandi, A. H., Gouya, M. M., et al. (2013). Clinical value of IS6110-based loop-mediated isothermal amplification for detection of Mycobacterium tuberculosis complex in respiratory specimens. J. Infect. 66, 487-493. doi: 10.1016/j.jinf.2013.02.005

Aryan, E., Makvandi, M., Farajzadeh, A., Huygen, K., Bifani, P., Mousavi, S. L., et al. (2010). A novel and more sensitive loop-mediated isothermal amplification assay targeting IS6110 for detection of Mycobacterium tuberculosis complex. Microbiol. Res. 165, 211-220. doi: 10.1016/j.micres.2009.05.001

Baker, L., Brown, T., Maisetti, J., and Drobniewski, F. A. (2004). Silent nucleotide polymorphisms and a phylogeny for Mycobacterium tuberculosis. Emerg. Infect. Dis. 10, 1568-1577. doi: 10.3201/eid1009.040046

Baptista, P., Pereira, E., Eaton, P., Doria, G., Miranda, A., Gomes, I., et al. (2008). Gold nanoparticles for the development of clinical diagnosis 
methods. Anal. Bioanal. Chem. 391, 943-950. doi: 10.1007/s00216-0071768-z

Becq, J., Gutierrez, M. C., Rosas-Magallanes, V., Rauzier, J., Gicquel, B., Neyrolles, O., et al. (2007). Contribution of horizontally acquired genomic islands to the evolution of the tubercle bacilli. Mol. Biol. Evol. 24, 1861-1871. doi: $10.1093 / \mathrm{molbev} / \mathrm{msm} 111$

Behr, M. A., Wilson, M. A., Gill, W. P., Salamon, H., Schoolnik, G. K., Rane, S., et al. (1999). Comparative genomics of BCG vaccines by whole genome DNA microarray. Science 284, 1520-1523. doi: 10.1126/science.284.5419.1520

Biek, R., O’Hare, A., Wright, D., Mallon, T., McCormick, C., Orton, R. J., et al. (2012). Whole genome sequencing reveals local transmission patterns of Mycobacterium bovis in sympatric cattle and badger populations. PLoS Pathog. 8:e1003008. doi: 10.1371/journal.ppat.1003008

Boehme, C. C., Nabeta, P., Henostroza, G., Raqib, R., Rahim, Z., Gerhardt, M., et al. (2007). Operational feasibility of using loop-mediated isothermal amplification for diagnosis of pulmonary tuberculosis in microscopy centers of developing countries. J. Clin. Microbiol. 45, 1936-1940. doi: 10.1128/JCM.02352-06

Botelho, A., Perdigão, J., Canto, A., Albuquerque, T., Leal, N., Macedo, R., et al. (2014). Pre-multidrug resistant Mycobacterium tuberculosis Beijing strain associated to disseminated tuberculosis in a pet dog. J. Clin. Microbiol. 52, 354-356. doi: 10.1128/JCM.02800-13

Brosch, R., Garnier, T., and Cole, S. T. (2000). Comparative genomics of the mycobacteria. Int. J. Med. Microbiol. 290, 143-152. doi: 10.1016/S14384221(00)80083-1

Brosch, R., Gordon, S. V., Billault, A., Garnier, T., Eiglmeier, K., Soravito, C., et al. (1998). Use of a Mycobacterium tuberculosis H37Rv bacterial artificial chromosome library for genome mapping, sequencing, and comparative genomics. Infect. Immun. 66, 2221-2229.

Brosch, R., Gordon, S. V., Marmiesse, M., Brodin, P., Buchrieser, C., Eiglmeier, K., et al. (2002). A new evolutionary scenario for the Mycobacterium tuberculosis complex. Proc. Natl. Acad. Sci. U.S.A. 99, 3684-3689. doi: 10.1073/pnas.052548299

Broughan, J. M., Downs, S. H., Crawshaw, T. R., Upton, P. A., Brewer, J., and Clifton-Hadley, R. S. (2013). Mycobacterium bovis infections in domesticated non-bovine mammalian species. Part 1: review of epidemiology and laboratory submissions in Great Britain 2004-2010. Vet. J. 198, 339-345. doi: 10.1016/j.tvjl.2013.09.006

Cantacessi, C., Hofmann, A., Campbell, B. E., and Gasser, R. B. (2014). "Impact of next-generation technologies on exploring socio-economically important parasites and developing new interventions," in Veterinary Infection Biology: Molecular Diagnostics and High-Throughput Strategies, eds M. V. Cunha and J. Inácio (New York, NY: Springer Science + Business Media, LLC) (in press).

Chen, J., Tsolaki, A. G., Shen, X., Jiang, X., Mei, J., and Gao, Q. (2007). Deletiontargeted multiplex PCR (DTM-PCR) for identification of Beijing/W genotypes of Mycobacterium tuberculosis. Tuberculosis (Edinb.) 87, 446-449. doi: 10.1016/j.tube.2007.05.014

Chowdry, V. K., Luo, Y., Widén, F., Qiu, H. J., Shan, H., Belák, S., et al. (2014) Development of a loop-mediated isothermal amplification assay combined with a lateral flow dipstick for rapid and simple detection of classical swine fever virus in the field. J. Virol. Methods 197, 14-18. doi: 10.1016/j.jviromet.2013. 11.013

Coetsier, C., Vannuffel, P., Blondeel, N., Denef, J. F., Cocito, C., and Gala, J. L. (2000). Duplex PCR for differential identification of Mycobacterium bovis, M. avium, and M. avium subsp. paratuberculosis in formalin-fixed paraffinembedded tissues from cattle. J. Clin. Microbiol. 38, 3048-3054.

Coll, F., Preston, M., Guerra-Assunção, J. A., Hill-Cawthorn, G., Harris, D., Perdigão, J., et al. (2014). PolyTB: a genomic variation map for Mycobacterium tuberculosis. Tuberculosis (Edinb.) 94, 346-354. doi: 10.1016/j.tube.2014.02.005

Corner, L. A. (1994). Post mortem diagnosis of Mycobacterium bovis infection in cattle. Vet. Microbiol. 40, 53-63. doi: 10.1016/0378-1135(94)90046-9

Corner, L. A., Gormley, E., and Pfeiffer, D. U. (2012). Primary isolation of Mycobacterium bovis from bovine tissues: conditions for maximising the number of positive cultures. Vet. Microbiol. 156, 162-171. doi: 10.1016/j.vetmic.2011.10.016

Coros, A., DeConno, E., and Derbyshire, K. M. (2008). IS6110, a Mycobacterium tuberculosis Complex-specific insertion sequence, is also present in the genome of Mycobacterium smegmatis, suggestive of lateral gene transfer among mycobacterial species. J. Bacteriol. 190, 3408-3410. doi: 10.1128/JB 00009-08
Costa, M., Veigas, B., Jacob, J., Santos, D., Gomes, J., Baptista, P., et al. (2013b). Low cost, safe, disposable, rapid and self-sustainable paper-based platform for diagnostic testing - Lab-on-Paper. Nanotechnology 25:094006. doi: 10.1088/09574484/25/9/094006

Costa, P., Amaro, A., Botelho, A., Inácio, J., and Baptista, P. V. (2010). Gold nanoprobes assay for identification of mycobacteria from the Mycobacterium tuberculosis complex. Clin. Microbiol. Infect. 16, 1464-1469. doi: 10.1111/j.14690691.2010.03120.x

Costa, P., Amaro, A., Ferreira, A. S., Machado, D., Albuquerque, T., Couto, I., et al. (2014a). Rapid identification of veterinary-relevant Mycobacterium tuberculosis complex species using 16S rDNA, IS6110 and Regions of Differencetargeted dual-labelled hydrolysis probes. J. Microbiol. Methods 107, 13-22. doi: 10.1016/j.mimet.2014.08.017

Costa, P., Couto, I., Viveiros, M., and Inácio, J. (2014b). "Nested and multiplex real time PCR using dual-labeled probes: detecting and discriminating Mycobacterium tuberculosis complex members in cultures and animal tissues," in Veterinary Infection Biology: Molecular Diagnostics and High-Throughput Strategies, eds M. V. Cunha and J. Inácio (New York, NY: Springer Science + Business Media LLC) (in press).

Costa, P., Ferreira, A. S., Amaro, A., Albuquerque, T., Botelho, A., Couto, I., et al. (2013a). Enhanced detection of tuberculous mycobacteria in animal tissues using a semi-nested probe-based real-time PCR. PLoS ONE 8:e81337. doi: 10.1371/journal.pone.0081337

Cousins, D. V., Williams, S. N., Ross, B. C., and Ellis, T. M. (1993). Use of a repetitive element isolated from Mycobacterium tuberculosis in hybridization studies with Mycobacterium bovis: a new tool for epidemiological studies of bovine tuberculosis. Vet. Microbiol. 37, 1-17. doi: 10.1016/0378-1135(93)90178-A

Cousins, D. V., Wilton, S. D., and Francis, B. R. (1991). Use of DNA amplification for the rapid identification of Mycobacterium bovis. Vet. Microbiol. 27, 187-195. doi: 10.1016/0378-1135(91)90010-D

Cunha, M. V., and Inácio, J. (2014). "Overview and challenges of molecular technologies in the veterinary microbiology laboratory," in Veterinary Infection Biology: Molecular Diagnostics and High-Throughput Strategies, eds M. V. Cunha and J. Inácio (New York, NY: Springer Science + Business Media LLC) (in press).

Djelouadji, Z., Raoult, D., Daffé, M., and Drancourt, M. (2008). A single-step sequencing method for the identification of Mycobacterium tuberculosis complex species. PLoS Negl. Trop. Dis. 2:e253. doi: 10.1371/journal.pntd.0000253

Drobniewski, F. A., Caws, M., Gibson, A., and Young, D. (2003). Modern laboratory diagnosis of tuberculosis. Lancet Infect. Dis. 3, 141-147. doi: 10.1016/S14733099(03)00544-9

Duarte, E. L., Domingos, M., Amado, A., and Botelho, A. (2008). Spoligotype diversity of Mycobacterium bovis and Mycobacterium caprae animal isolates. Vet Microbiol. 130, 415-421. doi: 10.1016/j.vetmic.2008.02.012

Erwin, P. C., Bemis, D. A., McCombs, S. B., Sheeler, L. L., Himelright, I. M., Halford, S. K., et al. (2004). Mycobacterium tuberculosis transmission from human to canine. Emerg. Infect. Dis. 10, 2258-2260. doi: 10.3201/eid1012.040094

Etter, E., Donado, P., Jori, F., Caron, A., Goutard, F., and Roger, F. (2006). Risk analysis and bovine tuberculosis, a re-emerging zoonosis. Ann. N.Y. Acad. Sci. 1081, 61-73. doi: 10.1196/annals.1373.006

Evans, J. T., Smith, E. G., Banerjee, A., Smith, R. M. M., Dale, J., Innes, J. A., et al. (2007). Cluster of human tuberculosis caused by Mycobacterium bovis: evidence for person-to-person transmission in the UK. Lancet 369, 1270-1276. doi: 10.1016/S0140-6736(07)60598-4

Fisanotti, J. C., Romano, M. I., Alito, A., Bigi, F., and Cataldi, A. (1997). An mpb-64 flanking sequence specific for Mycobacterium bovis. Res. Microbiol. 148, 427-435. doi: 10.1016/S0923-2508(97)83873-9

Ford, C., Yusim, K., Ioerger, T., Feng, S., Chase, M., Greene, M., et al. (2012). Mycobacterium tuberculosis - heterogeneity revealed through whole genome sequencing. Tuberculosis (Edinb.) 92, 194-201. doi: 10.1016/j.tube.2011.11.003

Garbaccio, S. G., and Cataldi, A. A. (2010). Evaluation of an immunomagnetic capture method followed by PCR to detect Mycobacterium bovis in tissue samples from cattle. Rev. Argent. Microbiol. 42, 247-253. doi: 10.1590/S032575412010000400002

Geojith, G., Dhanasekaran, S., Chandran, S. P., and Kenneth, J. (2011). Efficacy of loop mediated isothermal amplification (LAMP) assay for the laboratory identification of Mycobacterium tuberculosis isolates in a resource limited setting. J. Microbiol. Methods 84, 71-73. doi: 10.1016/j.mimet.2010.10.015 
Gordon, S. V., Brosch, R., Billault, A., Garnier, T., Eiglmeier, K., and Cole, S. T. (1999). Identification of variable regions in the genomes of tubercle bacilli using bacterial artificial chromosome arrays. Mol. Microbiol. 32, 643-655. doi: 10.1046/j.1365-2958.1999.01383.x

Gormley, E., Corner, L. A. L., Costello, E., and Rodriguez-Campos, S. (2014). Bacteriological diagnosis and molecular strain typing of Mycobacterium bovis and Mycobacterium caprae. Res. Vet. Sci. doi: 10.1016/j.rvsc.2014.04.010. [Epub ahead of print].

Gormley, E., Doyle, M. B., Fitzsimons, T., McGill, K., and Collins, J. D. (2006). Diagnosis of Mycobacterium bovis infection in cattle by use of the gamma-interferon (Bovigam) assay. Vet. Microbiol. 112, 171-179. doi: 10.1016/j.vetmic.2005.11.029

Granberg, F., Karlsson, O., Leijon, M., Liu, L., and Belák, S. (2014). "Molecular approaches to recognize relevant and emerging infectious diseases in animals," in Veterinary Infection Biology: Molecular Diagnostics and High-Throughput Strategies, eds M. V. Cunha and J. Inácio (New York, NY: Springer Science + Business Media LLC) (in press).

Grange, J. M., Yates, M. D., de Kantor, I. N., and Emerging and other communicable diseases, surveillance and control. (1996). "Guidelines for speciation within the Mycobacterium tuberculosis complex," in Report WHO/EMC/ZOO/96.4 (Geneva: World Health Organization), 1-18.

Grant, I. R., and Stewart, L. D. (2014). "Improved detection of Mycobacterium bovis in bovine tissues using immunomagnetic separation approaches," in Veterinary Infection Biology: Molecular Diagnostics and High-Throughput Strategies, eds M. V. Cunha and J. Inácio (New York, NY: Springer Science + Business Media LLC) (in press).

Gutacker, M. M., Smoot, J. C., Migliaccio, C. A. L., Ricklefs, S. M., Hua, S., Cousins, D. V., et al. (2002). Genome-wide analysis of synonymous Single Nucleotide Polymorphisms in Mycobacterium tuberculosis complex organisms: resolution of genetic relationships among closely related microbial strains. Genetics 162, 1533-1543.

Gutierrez, M. C., Brisse, S., Brosch, R., Fabre, M., Bahia, O., Marmiesse, M., et al. (2005). Ancient origin and gene mosaicism of the progenitor of Mycobacterium tuberculosis. PLoS Pathog. 1:e5. doi: 10.1371/journal.ppat.0010005

Halse, T. A., Escuyer, V. E., and Musser, K. A. (2011). Evaluation of a single-tube multiplex real-time PCR for differentiation of members of the Mycobacterium tuberculosis complex in clinical specimens. J. Clin. Microbiol. 49, 2562-2567. doi: 10.1128/JCM.00467-11

Hardstaff, J. L., Marion, G., Hutchings, M. R., and White, P. C. L. (2014). Evaluating the tuberculosis hazard posed to cattle from wildlife across Europe. Res. Vet. Sci. doi: 10.1016/j.rvsc.2013.12.002. [Epub ahead of print].

Heid, C. A., Stevens, J., Livak, K. J., and Williams, P. M. (1996). Real time quantitative PCR. Genome Res. 6, 986-994. doi: 10.1101/gr.6.10.986

Hines, N., Payeur, J. B., and Hoffman, L. J. (2006). Comparison of the recovery of Mycobacterium bovis isolates using the BACTEC MGIT 960 system, BACTEC 460 system, and Middlebrook 7H10 and 7H11 solid media. J. Vet. Diagn. Invest. 18, 243-250. doi: 10.1177/104063870601800302

Huard, R. C., Fabre, M., de Haas, P., Lazzarini, L. C., van Soolingen, D., Cousins, D., et al. (2006). Novel genetic polymorphisms that further delineate the phylogeny of the Mycobacterium tuberculosis complex. J. Bacteriol. 188, 4271-4287. doi: 10.1128/JB.01783-05

Huard, R. C., Lazzarini, L. C., Butler, W. R., van Soolingen, D., and Ho, J. L. (2003). PCR-based method to differentiate the subspecies of the Mycobacterium tuberculosis complex on the basis of genomic deletions. J. Clin. Microbiol. 41, 1637-1650. doi: 10.1128/JCM.41.4.1637-1650.2003

Iwamoto, T., Sonobe, T., and Hayashi, K. (2003). Loop-mediated isothermal amplification for direct detection of Mycobacterium tuberculosis complex, M. avium, and M. intracellulare in sputum samples. J. Clin. Microbiol. 41, 2616-2622. doi: 10.1128/JCM.41.6.2616-2622.2003

Jang, J., Becq, J., Gicquel, B., Deschavanne, P., and Neyrolles, O. (2008). Horizontally acquired genomic islands in the tubercle bacilli. Trends Microbiol. 16, 303-308. doi: 10.1016/j.tim.2008.04.005

Joseph, S. J., and Read, T. D. (2010). Bacterial population genomics and infectious disease diagnostics. Trends Biotechnol. 28, 611-618. doi: 10.1016/j.tibtech.2010.09.001

Köser, C. U., Ellington, M. J., Cartwright, E. J., Gillespie, S. H., Brown, N. M., Farrington, M., et al. (2012). Routine use of microbial whole genome sequencing in diagnostic and public health microbiology. PLoS Pathog. 8:e1002824. doi: 10.1371/journal.ppat.1002824
Kozlovac, J., and Schmitt, B. (2014). "Biosafety principles and practices for the veterinary diagnostic laboratory," in Veterinary Infection Biology: Molecular Diagnostics and High-Throughput Strategies, eds M. V. Cunha and J. Inácio (New York, NY: Springer Science + Business Media LLC) (in press).

Kubica, T., Rüsch-Gerdes, S., and Niemann, S. (2003). Mycobacterium bovis subsp. caprae caused one-third of human M. bovis-associated tuberculosis cases reported in Germany between 1999 and 2001. J. Clin. Microbiol. 41, 3070-3077. doi: 10.1128/JCM.41.7.3070-3077.2003

Langer, P., Waldrop, A. A., and Ward, D. C. (1981). Enzymatic synthesis of biotinlabeled polynucleotides: novel nucleic acid affinity probes. Proc. Natl. Acad. Sci. U.S.A. 78, 6633-76637. doi: 10.1073/pnas.78.11.6633

Liandris, E., Gazouli, M., Andreadou, M., Comor, M., Abazovic, N., Sechi, L. A., et al. (2009). Direct detection of unamplified DNA from pathogenic mycobacteria using DNA-derivatized gold nanoparticles. J. Microbiol. Methods 78, 260-264. doi: 10.1016/j.mimet.2009.06.009

Liébana, E., Aranaz, A., Mateos, A., Vilafranca, M., Gomez-Mampaso, E., Tercero, J. C., et al. (1995). Simple and rapid detection of Mycobacterium tuberculosis complex organisms in bovine tissue samples by PCR. J. Clin. Microbiol. 33, 33-36.

Maas, M., Michel, A. L., and Rutten, V. P. (2013). Facts and dilemmas in diagnosis of tuberculosis in wildlife. Comp. Immunol. Microbiol. Infect. Dis. 36, 269-285. doi: 10.1016/j.cimid.2012.10.010

Mahairas, G. G., Sabo, P. J., Hickey, M. J., Singh, D. C., and Stover, C. K. (1996). Molecular analysis of genetic differences between Mycobacterium bovis BCG and virulent M. bovis. J. Bacteriol. 178, 1274-1282.

Martinez, A. W., Phillips, S. R., Whitesides, G. M., and Carrilho, E. (2010). Diagnostics for the developing world: microfluidic paper-based analytical devices. Anal. Chem. 82, 3-10. doi: 10.1021/ac9013989

Martinez, A. W., Phillips, S. T., Butte, M. J., and Whitesides, G. M. (2007) Patterned paper as a platform for inexpensive, low-volume, portable bioassays. Angew. Chem. Int. Ed. Engl. 46, 1318-1320. doi: 10.1002/anie. 200603817

Michel, A. L., Müller, B., and van Helden, P. D. (2010). Mycobacterium bovis at the animal-human interface: a problem, or not? Vet. Microbiol. 140, 371-381. doi: 10.1016/j.vetmic.2009.08.029

Miller, J., Jenny, A., Rhyan, J., Saari, D., and Suarez, D. (1997). Detection of Mycobacterium bovis in formalin-fixed, paraffin-embedded tissues of cattle and elk by PCR amplification of an IS6110 sequence specific for Mycobacterium tuberculosis complex organisms. J. Vet. Diagn. Invest. 9, 244-249. doi: $10.1177 / 104063879700900304$

Mohamed, A. M., Abou El-Ella, G. A., and Nasr, E. A. (2009). Phenotypic and molecular typing of tuberculous and nontuberculous Mycobacterium species from slaughtered pigs in Egypt. J. Vet. Diagn. Invest. 21, 48-52. doi: 10.1177/104063870902100107

Mostowy, S., Cousins, D., Brinkman, J., Aranaz, A., and Behr, M. A. (2002). Genomic deletions suggest a phylogeny for the Mycobacterium tuberculosis complex. J. Infect. Dis. 186, 74-80. doi: 10.1086/341068

Mostowy, S., Inwald, J., Gordon, S., Martin, C., Warren, R., Kremer, K., et al. (2005). Revisiting the evolution of Mycobacterium bovis. J. Bacteriol. 187, 6386-6395. doi: 10.1128/JB.187.18.6386-6395.2005

Namouchi, A., Didelot, X., Schöck, U., Gicquel, B., and Rocha, E. P. (2012). After the bottleneck: genome-wide diversification of the Mycobacterium tuberculosis complex by mutation, recombination, and natural selection. Genome Res. 22 721-734. doi: 10.1101/gr.129544.111

Neill, S. D., Bryson, D. G., and Pollock, J. M. (2001). Pathogenesis of tuberculosis in cattle. Tuberculosis 81, 79-86. doi: 10.1054/tube.2000.0279

Niemann, S., Harmsen, D., Rusch-Gerdes, S., and Richter, E. (2000). Differentiation of clinical Mycobacterium tuberculosis complex isolates by gyrB DNA sequence polymorphism analysis. J. Clin. Microbiol. 38, 3231-3234.

Niemz, A., Ferguson, T. M., and Boyle, D. S. (2011). Point-of-care nucleic acid testing for infectious diseases. Trends Biotechnol. 29, 240-250. doi: 10.1016/j.tibtech.2011.01.007

Notomi, T., Okayama, H., Masubuchi, H., Yonekawa, T., Watanabe, K., Amino, N. et al. (2000). Loop-mediated isothermal amplification of DNA. Nucleic Acids Res. 28:E63. doi: 10.1093/nar/28.12.e63

Padilla, E., González, V., Manterola, J. M., Lonca, J., Pérez, A., Matas, L., et al. (2003). Evaluation of two different cell lysis methods for releasing mycobacterial nucleic acids in the INNO-LiPA mycobacteria test. Diagn. Microbiol. Infect. Dis. 46, 19-23. doi: 10.1016/S0732-8893(03)00010-5 
Padilla, E., González, V., Manterola, J. M., Pérez, A., Quesada, M. D., Gordillo, S., et al. (2004). Comparative evaluation of the new version of the INNOLiPA Mycobacteria and genotype Mycobacterium assays for identification of Mycobacterium species from MB/BacT liquid cultures artificially inoculated with mycobacterial strains. J. Clin. Microbiol. 42, 3083-3088. doi: 10.1128/JCM.42.7.3083-3088.2004

Pandey, B. D., Poudel, A., Yoda, T., Tamaru, A., Oda, N., Fukushima, Y., et al (2008). Development of an in-house loop-mediated isothermal amplification (LAMP) assay for detection of Mycobacterium tuberculosis and evaluation in sputum samples of Nepalese patients. J. Med. Microbiol. 57, 439-443. doi: 10.1099/jmm.0.47499-0

Parra, A., García, N., García, A., Lacombe, A., Moreno, F., Freire, F., et al. (2008). Development of a molecular diagnostic test applied to experimental abattoir surveillance on bovine tuberculosis. Vet. Microbiol. 127, 315-324. doi: 10.1016/j.vetmic.2007.09.001

Parsons, L. M., Brosch, R., Cole, S. T., Somoskövi, A., Loder, A., Bretzel, G., et al. (2002). Rapid and simple approach for identification of Mycobacterium tuberculosis complex isolates by PCR-based genomic deletion analysis. J. Clin. Microbiol. 40, 2339-2345. doi: 10.1128/JCM.40.7.2339-2345.2002

Pérez-Lago, L., Navarro, Y., and García-de-Viedma, D. (2013). Current knowledge and pending challenges in zoonosis caused by Mycobacterium bovis: a review. Res. Vet. Sci. doi: 10.1016/j.rvsc.2013.11.008. [Epub ahead of print].

Picken, R. N., Plotch, S. J., Wang, Z., Lin, B. C., Donegan, J. J., and Yang, H. L. (1988). DNA probes for mycobacteria. I. Isolation of DNA probes for the identification of Mycobacterium tuberculosis complex and for mycobacteria other than tuberculosis (MOTT). Mol. Cell. Probes 2, 111-124. doi: 10.1016/08908508(88)90033-3

Pinsky, B. A., and Banaei, N. (2008). Multiplex real-time PCR assay for rapid identification of Mycobacterium tuberculosis complex members to the species level. J. Clin. Microbiol. 46, 2241-2246. doi: 10.1128/JCM.00347-08

Plikaytis, B. B., Eisenach, K. D., Crawford, J. T., and Shinnick, T. M. (1991). Differentiation of Mycobacterium tuberculosis and Mycobacterium bovis BCG by a polymerase chain reaction assay. Mol. Cell. Probes 5, 215-219. doi: 10.1016/0890-8508(91)90043-J

Pollock, J. M., and Neill, S. D. (2002). Mycobacterium bovis infection and tuberculosis in cattle. Vet. J. 163, 115-127. doi: 10.1053/tvjl.2001.0655

Pollock, J. M., Welsh, M. D., and McNair, J. (2005). Immune responses in bovine tuberculosis: towards new strategies for the diagnosis and control of disease. Vet. Immunol. Immunopathol. 108, 37-43. doi: 10.1016/j.vetimm.2005.08.012

Pounder, J. I., Anderson, C. M., Voelkerding, K. V., Salfinger, M., Dormandy, J., Somoskovi, A., et al. (2010). Mycobacterium tuberculosis complex differentiation by genomic deletion patterns with multiplex polymerase chain reaction and melting analysis. Diagn. Microbiol. Infect. Dis. 67, 101-105. doi: 10.1016/j.diagmicrobio.2009.12.014

Radomski, N., Kreitmann, L., McIntosh, F., and Behr, M. A. (2013). The critical role of DNA extraction for detection of mycobacteria in tissues. PLoS ONE 8:e78749. doi: 10.1371/journal.pone.0078749

Reddington, K., O’Grady, J., Dorai-Raj, S., Niemann, S., van Soolingen, D., and Barry, T. (2011). A novel multiplex real-time PCR for the identification of mycobacteria associated with zoonotic tuberculosis. PLoS ONE 6:e23481. doi: 10.1371/journal.pone.0023481

Reddington, K., Zumla, A., Bates, M., van Soolingen, D., Niemann, S., Barry, T., et al. (2012). SeekTB - A two stage multiplex real-time PCR based method for the differentiation of the Mycobacterium tuberculosis complex. J. Clin. Microbiol. 50, 2203-2206. doi: 10.1128/JCM.00718-12

Rodriguez-Campos, S., Smith, N. H., Boniotti, M. B., and Aranaz, A. (2014). Overview and phylogeny of Mycobacterium tuberculosis complex organisms: implications for diagnostics and legislation of bovine tuberculosis. Res. Vet. Sci. doi: 10.1016/j.rvsc.2014.02.009. [Epub ahead of print]

Rodríguez, E., Sánchez, L. P., Pérez, S., Herrera, L., Jiménez, M. S., Samper, S., et al. (2009). Human tuberculosis due to Mycobacterium bovis and M. caprae in Spain, 2004-2007. Int. J. Tuberc. Lung Dis. 13, 1536-1541.

Roetzer, A., Diel, R., Kohl, T. A., Rückert, C., Nübel, U., Blom, J., et al. (2013). Whole genome sequencing versus traditional genotyping for investigation of a Mycobacterium tuberculosis outbreak: a longitudinal molecular epidemiological study. PLoS Med. 10:e1001387. doi: 10.1371/journal.pmed. 1001387

Roring, S., Hughes, M. S., Skuce, R. A., and Neill, S. D. (2000). Simultaneous detection and strain differentiation of Mycobacterium bovis directly from bovine tissue specimens by spoligotyping. Vet. Microbiol. 74, 227-236. doi: 10.1016/S0378-1135(00)00189-9

Rosa, A. M., Louro, A. F., Martins, S. A., Inácio, J., Azevedo, A. M., and Prazeres, D. M. (2014). Capture and detection of DNA hybrids on paper via the anchoring of antibodies with fusions of carbohydrate binding modules and ZZ-domains. Anal. Chem. 86, 4340-4347. doi: 10.1021/ac5001288

Rosas-Magallanes, V., Deschavanne, P., Quintana-Murci, L., Brosch, R., Gicquel, B., and Neyrolles, O. (2006). Horizontal transfer of a virulence operon to the ancestor of Mycobacterium tuberculosis. Mol. Biol. Evol. 23, 1129-1135. doi: 10.1093/molbev/msj120

Rozand, C. (2014). Paper-based analytical devices for point-of-care infectious disease testing. Eur. J. Clin. Microbiol. Infect. Dis. 33, 147-156. doi: 10.1007/s10096 013-1945-2

Rua-Domenech, R. (2006). Human Mycobacterium bovis infection in the United Kingdom: incidence, risks, control measures and review of the zoonotic aspects of bovine tuberculosis. Tuberculosis 86, 77-109. doi: 10.1016/j.tube.2005.05.002 Rua-Domenech, R., Goodchild, A. T., Vordermeier, H. M., Hewinson, R. G., Christiansen, K. H., and Clifton-Hadley, R. S. (2006). Ante mortem diagnosis of tuberculosis in cattle: a review of the tuberculin tests, gamma-interferon assay and other ancillary diagnostic techniques. Res. Vet. Sci. 81, 190-210. doi: 10.1016/j.rvsc.2005.11.005

Saiki, R. K., Gelfand, D. H., Stoffel, S., Scharf, S. J., Higuchi, R., Horn, G. T., et al. (1988). Primer-directed enzymatic amplification of DNA with a thermostable DNA polymerase. Science 239, 487-491. doi: 10.1126/science.2448875

Saiki, R. K., Scharf, S., Faloona, F., Mullis, K. B., Horn, G. T., Erlich, H. A., et al. (1985). Enzymatic amplification of beta-globin genomic sequences and restriction site analysis for diagnosis of sickle cell anemia. Science 230, 1350-1354. doi: 10.1126/science. 2999980

Santos, N., Geraldes, M., Afonso, A., Almeida, V., and Correia-Neves, M. (2010). Diagnosis of tuberculosis in the wild boar (Sus scrofa): a comparison of methods applicable to hunter-harvested animals. PLoS ONE 5:e12663. doi: 10.1371/journal.pone.0012663

Saunders, N., and Sharp, I. (2014). "Validation of molecular diagnostic assays and quality assurance and control in the veterinary laboratory," in Veterinary Infection Biology: Molecular Diagnostics and High-Throughput Strategies, eds M. V. Cunha and J. Inácio (New York, NY: Springer Science + Business Media LLC) (in press).

Savelkoul, P. H., Catsburg, A., Mulder, S., Oostendorp, L., Schirm, J., Wilke, H., et al. (2006). Detection of Mycobacterium tuberculosis complex with real time PCR: comparison of different primer-probe sets based on the IS6110 element. J. Microbiol. Methods 66, 177-180. doi: 10.1016/j.mimet.2005.12.003

Schiller, I., Waters, W. R., Vordermeier, H. M., Jemmi, T., Welsh, M., Keck, N. et al. (2011). Bovine tuberculosis in Europe from the perspective of an officially tuberculosis free country: trade, surveillance and diagnostics. Vet. Microbiol. 151, 153-159. doi: 10.1016/j.vetmic.2011.02.039

Schmidt, V., Schneider, S., Schlömer, J., Krautwald-Junghanns, M., and Richter, E. (2008). Transmission of tuberculosis between men and pet birds: a case report. Avian Pathol. 37, 589-592. doi: 10.1080/03079450802428901

Smith, N. H., Gordon, S. V., Rua-Domenech, R., Clifton-Hadley, R. S., and Hewinson, R. G. (2006). Bottlenecks and broomsticks: the molecular evolution of Mycobacterium bovis. Nat. Rev. Microbiol. 4, 670-681. doi: 10.1038/nrmicrol 142

Smith, N. H., Hewinson, R. G., Kremer, K., Brosch, R., and Gordon, S. V. (2009). Myths and misconceptions: the origin and evolution of Mycobacterium tuberculosis. Nat. Rev. Microbiol. 7, 537-544. doi: 10.1038/nrmicro2165

Southern, E. M. (1975). Detection of specific sequences among DNA fragments separated by gel electrophoresis. J. Mol. Biol. 98, 503-517. doi: 10.1016/S00222836(75)80083-0

Sreevatsan, S., Pan, X., Stockbauer, K. E., Connell, N. D., Kreiswirth, B. N., Whittam, T. S., et al. (1997). Restricted structural gene polymorphism in the Mycobacterium tuberculosis complex indicates evolutionarily recent global dissemination. Proc. Natl. Acad. Sci. U.S.A. 94, 9869-9874. doi: 10.1073/pnas.94.18.9869

Stewart, L. D., McNair, J., McCallan, L., Gordon, A., and Grant, I. R. (2013). Improved detection of Mycobacterium bovis infection in bovine lymph node tissue using immunomagnetic separation (IMS)-based methods. PLoS ONE 8:e58374. doi: 10.1371/journal.pone.0058374

Sunder, S., Lanotte, P., Godreuil, S., Martin, C., Boschiroli, M. L., and Besnier, J. M. (2009). Human-to-human transmission of tuberculosis caused by 
Mycobacterium bovis in immunocompetent patients. J. Clin. Microbiol. 47, 1249-1251. doi: 10.1128/JCM.02042-08

Supply, P., Marceau, M., Mangenot, S., Roche, D., Rouanet, C., Khanna, V., et al. (2013). Genomic analysis of smooth tubercle bacilli provides insights into ancestry and pathoadaptation of Mycobacterium tuberculosis. Nat. Genet. 45, 172-179. doi: 10.1038/ng.2517

Sweeney, F. P., Courtenay, O., Hibberd, V., Hewinson, R. G., Reilly, L. A., Gaze, W. H., et al. (2007). Environmental monitoring of Mycobacterium bovis in badger feces and badger sett soil by real-time PCR, as confirmed by immunofluorescence, immunocapture, and cultivation. Appl. Environ. Microbiol. 73, 7471-7473. doi: 10.1128/AEM.00978-07

Sweeney, F. P., Courtenay, O., Ul-Hassan, A., Hibberd, V., Reilly, L. A., and Wellington, E. M. (2006). Immunomagnetic recovery of Mycobacterium bovis from naturally infected environmental samples. Lett. Appl. Microbiol. 2, 460-462. doi: 10.1111/j.1472-765X.2006.01983.x

Taylor, G. M., Worth, D. R., Palmer, S., Jahans, K., and Hewinson, R. G. (2007). Rapid detection of Mycobacterium bovis DNA in cattle lymph nodes with visible lesions using PCR. BMC Vet. Res. 3:12. doi: 10.1186/1746-6148-3-12

Taylor, M. J., Hughes, M. S., Skuce, R. A., and Neill, S. D. (2001). Detection of Mycobacterium bovis in bovine clinical specimens using realtime fluorescence and fluorescence resonance energy transfer probe rapidcycle PCR. J. Clin. Microbiol. 39, 1272-1278. doi: 10.1128/JCM.39.4.12721278.2001

Teles, F., and Fonseca, L. P. (2014). "Nucleic acid testing, new platforms and nanotechnology for point-of-decision diagnosis of animal pathogens," in Veterinary Infection Biology: Molecular Diagnostics and High-Throughput Strategies, eds M. V. Cunha and J. Inácio (New York, NY: Springer Science + Business Media LLC) (in press).

Thacker, T. C., Harris, B., Palmer, M. V., and Waters, W. R. (2011). Improved specificity for detection of Mycobacterium bovis in fresh tissues using IS6110 real-time PCR. BMC Vet. Res. 7:50. doi: 10.1186/1746-6148-7-50

Thierry, D., Chureau, C., Aznar, C., and Guesdon, J. L. (1992). The detection of Mycobacterium tuberculosis in uncultured clinical specimens using the polymerase chain reaction and a non-radioactive DNA probe. Mol. Cell. Probes 6, 181-191. doi: 10.1016/0890-8508(92)90015-P

Torres-Gonzalez, P., Soberanis-Ramos, O., Martinez-Gamboa, A., Chavez-Mazari, B., Barrios-Herrera, M. T., Torres-Rojas, M., et al. (2013). Prevalence of latent and active tuberculosis among dairy farm workers exposed to cattle infected by Mycobacterium bovis. PLoS Negl. Trop. Dis. 7:e2177. doi: 10.1371/journal.pntd.0002177

Van Borm, S., Belák, S., Freimanis, G., Fusaro, A., Granberg, F., Hoper, D., et al. (2014). "Next-Generation Sequencing in veterinary medicine: how can the massive amount of information arising from high-throughput technologies improve diagnosis, control and management of infectious diseases?", in Veterinary Infection Biology: Molecular Diagnostics and High-Throughput Strategies, eds M. V. Cunha and J. Inácio (New York, NY: Springer Science + Business Media LLC) (in press).

van Ingen, J., Rahim, Z., Mulder, A., Boeree, M. J., Simeone, R., Brosch, R., et al. (2012). Characterization of Mycobacterium orygis as M. tuberculosis complex subspecies. Emerg. Infect. Dis. 18, 653-655. doi: 10.3201/eid1804.110888

Veigas, B., Jacob, J. M., Costa, M. N., Santos, D. S., Viveiros, M., Inácio, J., et al. (2012). Gold on paper-paper platform for Au-nanoprobe TB detection. Lab Chip 12, 4802-4808. doi: 10.1039/c2lc40739f
Vella, S. J., Beattie, P., Cademartiri, R., Laromaine, A., Martinez, A. W., Phillips, S. T., et al. (2012). Measuring markers of liver function using a micropatterned paper device designed for blood from a fingerstick. Anal. Chem. 84, 2883-2891. doi: $10.1021 / \mathrm{ac} 203434 \mathrm{x}$

Veyrier, F. J., Dufort, A., and Behr, M. A. (2011). The rise and fall of the Mycobacterium tuberculosis genome. Trends Microbiol. 19, 156-161. doi: 10.1016/j.tim.2010.12.008

Veyrier, F., Pletzer, D., Turenne, C., and Behr, M. A. (2009). Phylogenetic detection of horizontal gene transfer during the step-wise genesis of Mycobacterium tuberculosis. BMC Evol. Biol. 9:196. doi: 10.1186/1471-2148-9-196

Wang, J., and Behr, M. A. (2014). Building a better bacillus: the emergence of Mycobacterium tuberculosis. Front. Microbiol. 5:139. doi: 10.3389/fmicb.2014.00139

Wards, B. J., Collins, D. M., and de Lisle, G. W. (1995). Detection of Mycobacterium bovis in tissues by polymerase chain reaction. Vet. Microbiol. 43, 227-240. doi: 10.1016/0378-1135(94)00096-F

Warren, R. M., Gey van Pittius, N. C., Barnard, M., Hesseling, A., Engelke, E., de Kock, M., et al. (2006). Differentiation of Mycobacterium tuberculosis complex by PCR amplification of genomic regions of difference. Int. J. Tuberc. Lung Dis. $10,818-822$.

Wayne, L. G., and Kubica, G. P. (1986). "The mycobacteria," in Bergey's Manual of Systemic Bacteriology, Vol. 2, eds P. H. A. Sneath and J. G. Holt (Baltimore, MD: The Williams \& Wilkins Co), 1435-1457.

WHO. (2011). Global Tuberculosis Control: WHO Report 2011. Geneva: World Health Organization.

Williams, P. M. (2009). The beginnings of real-time PCR. Clin. Chem. 55, 833-834. doi: 10.1373/clinchem.2008.122226

Yuan, L.-Y., Li, Y., Wang, M., Ke, Z.-Q., Xu, W.-Z. (2014). Rapid and effective diagnosis of pulmonary tuberculosis with novel and sensitive loop-mediated isothermal amplification (LAMP) assay in clinical samples: a meta-analysis. J. Infect. Chemother. 20, 86-92. doi: 10.1016/j.jiac.2013.07.003

Zhang, J., Zhang, G.-H., Yang, L., Huang, R., Zhang, Y., Jia, K., et al. (2011). Development of a loop-mediated isothermal amplification assay for the detection of Mycobacterium bovis. Vet. J. 187, 393-396. doi: 10.1016/j.tvjl.2010. 01.001

Conflict of Interest Statement: The authors declare that the research was conducted in the absence of any commercial or financial relationships that could be construed as a potential conflict of interest.

Received: 11 July 2014; paper pending published: 11 September 2014; accepted: 25 September 2014; published online: 15 October 2014.

Citation: Costa P, Botelho A, Couto I, Viveiros M and Inácio J (2014) Standing of nucleic acid testing strategies in veterinary diagnosis laboratories to uncover Mycobacterium tuberculosis complex members. Front. Mol. Biosci. 1:16. doi: 10.3389/ fmolb.2014.00016

This article was submitted to Molecular Diagnostics, a section of the journal Frontiers in Molecular Biosciences.

Copyright (c) 2014 Costa, Botelho, Couto, Viveiros and Inácio. This is an openaccess article distributed under the terms of the Creative Commons Attribution License (CC BY). The use, distribution or reproduction in other forums is permitted, provided the original author(s) or licensor are credited and that the original publication in this journal is cited, in accordance with accepted academic practice. No use, distribution or reproduction is permitted which does not comply with these terms. 